\title{
The perception of midwives regarding psychosocial risk assessment during antenatal care
}

\author{
Authors: \\ Johanna M. Mathibe-Neke ${ }^{1}$ \\ Allan Rothberg ${ }^{2}$ \\ Gayle Langley ${ }^{2}$ \\ Affiliations: \\ ${ }^{1}$ Department of Health \\ Studies, University of South \\ Africa, South Africa \\ ${ }^{2}$ Faculty of Health Sciences, \\ University of Witwatersrand, \\ South Africa
}

\section{Correspondence to:}

Johanna Mathibe-Neke

Email:

mathijm@unisa.ac.za

Postal address:

PO Box 87205, Houghton

2041, South Africa

Dates:

Received: 16 Apr. 2013

Accepted: 29 Nov. 2013

Published: 22 May 2014

How to cite this article:

Mathibe-Neke, J.M.,

Rothberg, A. \& Langley,

G., 2014, 'The perception

of midwives regarding

psychosocial risk assessment

during antenatal care', Health

SA Gesondheid 19(1), Art.

\#742, 9 pages. http://dx.doi.

org/10.4102/hsag.v19i1.742

\section{Copyright:}

(C) 2014. The Authors.

Licensee: AOSIS

OpenJournals. This work

is licensed under the

Creative Commons

Attribution License.
Read online:

Scan this $Q R$ code with your smart phone or mobile device to read online.
Background: The physiological and psychological changes caused by pregnancy may increase a woman's vulnerability to depression, which may in turn have adverse effects on both maternal and foetal wellbeing. Inadequate psychosocial risk assessment of women by midwives may lead to lack of psychosocial support during pregnancy and childbirth. Pregnant women who lack psychosocial support may experience stress, anxiety and depression that could possibly affect foetal wellbeing.

Objective: The objective of this study was to explore and describe the perception of psychosocial risk assessment and psychosocial care by midwives providing antenatal care to pregnant women.

Method: An interpretive and descriptive qualitative approach was adopted. Three focus group interviews were conducted with midwives working in three Maternal Obstetric Units in Gauteng Province, using a semi-structured interview guide. The constant comparison data analysis approach was used.

Results: Findings revealed that midwives are aware of and have encountered a high prevalence of psychosocial problems in pregnant women. Furthermore, they acknowledged the importance of psychosocial care for pregnant women although they stated that they were not equipped adequately to offer psychosocial assessment and psychosocial care.

Conclusion: The findings provided a basis for incorporation of psychosocial care into routine antenatal care.

Agtergrond: Die fisiologiese en psigologiese veranderings wat deur swangerskap veroorsaak word, kan 'n vrou se kwetsbaarheid vir depressie verhoog. Dit kan op sy beurt negatiewe gevolge vir sowel die moeder as die fetus se welstand hê. As vroedvroue nie voldoende psigososiale riskio-assesserings op swanger vrouens doen nie, kan dit tot ' $n$ gebrek aan psigososiale ondersteuning tydens die swangerskap en geboorte lei. Swanger vrouens wat ' $n$ gebrek aan psigososiale ondersteuning het, kan stres, angs en depressie ervaar wat weer die fetus se welstand kan beïnvloed.

Doelwit: Die doelwit van hierdie studie was om die persepsies van vroedvroue, wat voorgeboortesorg aan swanger vrouens bied, te ondersoek en te beskryf sover dit hulle persepsies oor psigososiale risiko-assessering en psigososiale aangaan.

Metode: 'n Interpretatiewe en beskrywende kwalitatiewe benadering is gevolg. Drie fokusgroep-onderhoude is deur middel van ' $n$ gestruktureerde onderhoudsgids gevoer met verloskundiges wat in drie voorgeboorteklinieke in die Gauteng Provinsie werksaam is. 'n Benadering tot data-analise wat van voortdurende vergelyking gebruik maak, is gevolg.

Resultate: Die studie het aan die lig gebring dat verloskundiges bewus is van psigososiale probleme onder swanger vroue en dat die prevalensie van sulke probleme onder swanger vroue hoog is. Vroedvroue erken die belang van psigososiale sorg aan swanger vroue alhoewel hulle nie toereikend toegerus is om psigososiale assessering en -sorg te verleen nie.

Gevolgtrekking: Die bevindinge stel ' $n$ basis daar vir die insluiting van psigososiale sorg in roetine voorgeboortesorg.

\section{Introduction and background}

The concept of psychosocial stressors experienced during pregnancy encompasses life experiences, including changes in personal life, job status, family makeup, housing and the possibility of domestic violence. All of these require adaptive coping mechanisms on the part of the pregnant woman, which can be facilitated through support by a midwife (Coussons-Read et al. 2005:625-626).

Pregnancy, birth and parenthood are phases in life that create demands on a woman's ability to adapt: physically, psychologically and socially. The physical discomfort of pregnancy, accompanied 
by the anticipation of childbirth and the responsibility of parenthood, often causes anxiety and emotional changes that might lead to complications, for example, preterm labour and delivery (Mamelle 2001:268).

Previous conflicts in childhood and adulthood are often reactivated during pregnancy and can make some women vulnerable as they become less prepared for the changes brought about by pregnancy and motherhood. It has been stated that these physiological and psychosocial adjustments in pregnancy may increase the women's vulnerability to depression, which may in turn have an adverse effect on both maternal and foetal wellbeing (Suppaseemanont 2006:11).

Reflecting on literature, a systematic review of 16 studies on antenatal screening for postnatal depression by Austin and Lumley (2003:13), which involved 23000 women, revealed that $10 \%-67 \%$ were at risk of postnatal depression. The preliminary evidence suggested that the introduction of a screening tool to aid early detection and diagnosis of depression helped to raise awareness of psychosocial maternal risks amongst healthcare providers who offer antenatal care services.

According to the World Health Organization (WHO 1998:13-14), maternal risk is defined as the probability of experiencing various levels of injuries or even dying as a result of pregnancy or childbirth. Risk assessment is not new to midwives as they have always been mindful of the possibility of risks during pregnancy and delivery. Midwives normally use their knowledge, skills and available evidence in order to assess any potential risks associated with pregnancy throughout the childbearing process. The WHO recommended that physiological and psychosocial assessment should commence during the first visit, as part of a comprehensive assessment, at which time the midwife elicits medical, surgical, social, psychological and obstetrical history, which may affect the outcome of the current pregnancy. The assessment should be reviewed during subsequent antenatal visits.

Risk screening, according to the WHO (1998:13-14), involves using a list of risk factors and some form of scoring system to classify pregnant women into specific risk categories, typically high risk or low risk, using cut-off points or thresholds. The focus of risk screening is to detect early symptoms and predict the likelihood of complications. The intention is to predict problems before they occur and, as such, take appropriate action by providing optimal maternal care. According to Feldman (2000), the overall aim of psychosocial risk assessment during pregnancy is to screen the pregnant population or family and provide care and appropriate intervention to women in need, which would reduce the risk for psychosocial stress and promote a positive attitude towards childbirth. In addition to minimising maternal distress, psychosocial support inspires healthier lifestyles and discourages behaviours such as smoking, substance abuse and poor nutritional intake, thus promoting a healthier pregnancy outcome.

Mercer (1986), as quoted by Hildingsson and Häggström (1999:83), described the purpose of social support as making women feel respected and valued. The quality of support is of more value than the quantity. Furthermore, research has revealed a growing body of knowledge regarding the negative influence of psychosocial factors on the outcome of pregnancy. A cross-sectional study to identify a relationship between life stress, perceived social support and symptoms of depression and anxiety was conducted by Glazier et al. (2004:252). Based on the results, the researchers recommended that psychosocial assessment of pregnant women and their partners should be conducted as routine care. Several authors, for example, Handwerker (1994). Lupton (1999) and Saxell (2000), as quoted by Stahl and Hundley (2003:299), indicated that risk assessment during childbirth is made more complex by the differences in the perceptions of risks between midwives and pregnant women. Risks, from a midwife's perspective, are based on specialised knowledge and training, epidemiology, personal values and experience, whereas a woman's understanding of risk is far more contextual, individualised and embedded in her social environment and everyday life experience.

The prenatal care guidelines by the Group Health Incorporated (2008) advocate for psychosocial risk assessment, namely, screening for economic, social and psychological status, emotional status, smoking, drug and alcohol abuse, domestic violence and history of sexual assault to be part of the overall risk assessment.

The methodological approach in this study is a mixedmethod approach, combining quantitative and qualitative research techniques, methods and approaches to address psychosocial risk assessment and psychosocial support by midwives during antenatal care. The methodology was aimed at accommodating the diverse population involved in the study, the nature of data being sought and the number of investigations conducted, involving the collection, analysis and interpretation of quantitative and qualitative data. Data sources for the major study included midwives, midwifery experts, pregnant women and midwifery education regulations and curricula.

\section{Problem statement}

As a midwifery educator, the researcher observed that psychosocial risk assessment and psychosocial support were given insufficient attention in midwifery education and by midwives who provide antenatal care to pregnant women. Historically, the definition of maternal risk largely includes medical factors, with only a few psychosocial and socioeconomic factors being considered, specifically psychosocial history-taking by midwives during antenatal care.

Menon, Musonda and Glazebrook (2010:361) indicated that it is important for health professionals to ask pregnant women about their feelings related to the pregnancy, childbirth and motherhood and to give women who express fear an opportunity to discuss this because psychosocial interventions have proved to be beneficial in providing comprehensive antenatal care. In the South African context, 
antenatal care is usually offered in the form of routine physical assessment and care, with limited or no psychosocial assessment and care.

\section{Aim and significance of the study}

The aim of the study was to establish the perception and raise awareness of the importance of psychosocial care for pregnant women by conducting focus group discussions with midwives. The study aimed at closing the gap between the physical care and psychosocial care that is offered to women by midwives during antenatal care. The ultimate goal is for women to be provided with a routine holistic antenatal care service.

\section{Research objectives}

1. To explore and describe midwives' awareness, knowledge and understanding of psychosocial risk assessment and support.

2. To establish whether midwives conduct psychosocial assessment during antenatal care.

3. To develop recommendations for psychosocial care based on the study findings, with a focus on providing appropriate psychosocial support that would enhance maternal and foetal wellbeing.

\section{Key concepts}

Antenatal care is a part of reproductive health, a level of care in the maternity cycle that is given to a woman from conception until the onset of labour. A midwife or an obstetrician provides this care. The overall objective of antenatal care is to ensure the best possible pregnancy outcomes for pregnant women and their babies, through optimal physical, social and psychological preparation before delivery (Dragonas \& Christodoulou 1998:127-130; Gauteng Department of Health 1997:3). The National Collaborating Centre for Women and Children's Health states that antenatal care is not an independent entity as each woman brings her physical, personal, emotional and cultural realities and her experiences of pregnancy, whereas a midwife brings her knowledge and expertise of the childbearing process to manage the pregnancy (National Institute for Health and Care Excellence 2003:26).

Psychosocial risk assessment is an evaluation of an individual's mental health, social status and functional capacity. The individual's physical status, appearance and behaviour are observed for factors that may indicate emotional distress or mental illness. Observations include posture, facial expressions, manner of dress, speech and thought patterns, degree of motor activity and level of consciousness. The individual is questioned concerning activities of daily living, including work schedule and social and leisure activities. Data should include the individual's response to and methods of coping with stress, relationships, cultural orientation, unemployment or change of employment, change of residence, marriage, divorce, or death of a loved one (Anderson \& Anderson 1990:738; Anderson, Harris \& Madl 1998:237-251)
Psychosocial support is the provision of assistance and support in the management of identified psychological or social problems or risks. Bryce, Stanley and Enkin (1988:20) define psychological or social comfort, assistance and the information one receives through formal and informal interaction with an individual or group, with the focus on providing information, support and referral for psychological, social issues and needs. For the purpose of this study, support refers to the functions that are rendered by midwives in order to reduce stress and social problems in a pregnant woman and to make her feel accepted through enhancing her self-esteem, health and emotional wellbeing, thus enabling her to make appropriate psychosocial adjustments.

\section{Contribution to field}

It is hoped that the findings of the study would indicate the extent of the midwives' understanding of the importance of and the implementation of psychosocial care to pregnant women. The midwives' responses would contribute to the formulation of guidelines.

\section{Research method and design Design}

An interpretive qualitative design was used, characterised by a search for meaning and understanding, the use of an inductive investigative strategy and a rich presentation and discussion of findings (Merriam 2002:1-10). This design was used in this study in order for the researcher to establish an understanding of how midwives make meaning of the phenomenon psychosocial care for a pregnant woman. The researcher was the primary instrument for data collection and analysis. Inductive reasoning was used to discover the system of psychosocial care as provided by midwives during antenatal care. Deductive reasoning was used to uncover the midwives' knowledge and understanding of psychosocial assessment and psychosocial care.

\section{Population, sampling and data collection}

The population consisted of all midwives working at three Maternal Obstetric Units in Gauteng Province that offer antenatal care services at primary healthcare level. All midwives who worked in the stated clinics were purposively selected to participate in focus group discussions (Merriam 2002:18-22). The clinic manager organised the venue and coordinated the group by ensuring that they all had information about the study and are aware that participation is voluntary and that they may withdraw at any stage of the discussion. Focus group discussions were conducted in a consultation room within each clinic. The midwives in each group were based at the same clinic. Three focus groups of two groups of five midwives and one group of six midwives discussions were conducted. These discussions were used to obtain insight into the understanding, attitudes, opinions and perceptions of midwives regarding psychosocial risk assessment and psychosocial support during antenatal care. The midwives were informed in full about the study and had 
three months in which to decide on participation. A consent form for participation was attached to the information letter and signed preparticipation.

An interview guide with open-ended questions was used. The interview guide was compiled from the preliminary results of self-administered questionnaires completed by pregnant women and the findings of focus group discussions which had been conducted with pregnant women. Five categories of open-ended questions, an opening, introductory, transition, key and ending question as described by Krueger (2002:6-8) were included. One of the inclusion criteria required midwives to have provided care to pregnant women for at least two years, in order to be able to share information about psychosocial risk assessment and psychosocial support. The researcher conducted each focus group and served as an observer, listener, moderator and analyser using an inductive process. Data were tape recorded and transcribed verbatim. Within-group and across-group data saturation was reached with the third focus group. The duration of the interviews was approximately 55 minutes.

\section{Data analysis}

The constant comparison analysis method (Onwuegbuzie et al. 2009:5) was applied as it provides a clear series of steps which can easily manage large amounts of complex data and allows the researcher to assess data saturation in general and across-group saturation. Three major stages that were applied are open coding, axial coding and selective coding, as data were initially grouped into small units, then codes were used to group data into categories and, lastly, the researcher developed themes that expressed the content of each of the groups under axial coding.

\section{Philosophical perspective}

A holistic ideology described by the American Holistic Nurses Association (AHNA) (Frisch 2001), which is ideal for all healthcare practitioners, was used as a theoretical framework to guide this study. With reference to the AHNA's description of holistic nursing, holistic antenatal care relates to the identification by a midwife of the interrelationship of the bio-psycho-socio-spiritual dimensions of a pregnant woman and understanding of the woman as a unitary whole in a mutual process with her environment. For the AHNA, practising holistic nursing requires midwives to integrate self-care, self-responsibility, spirituality and reflection on their lives, which will make the midwife interconnect with self, others, nature and God. This awareness may further enhance the midwife's understanding of each woman as an individual. A healthcare practitioner who believes in holism often considers and offers complementary and alternative forms of healthcare as options (Walter 1999).

\section{Findings}

All 16 participants were females. The discussions were generally relaxed, aided by the fact that the midwives were a working group and knew one another. This allowed them to relate to each other's comments. They were able to challenge one another and self-disclosure was also promoted. Focus group discussions produced data that provided insight into the understanding, attitudes and opinions of midwives regarding psychosocial risk assessment and psychosocial support. Typically, midwives defined a situation which presented a particular psychosocial problem, then described the action taken by a midwife and the outcome of the interaction. This approach provided the researcher with an overall view of the participants' perceptions of psychosocial care. The stories were analysed by viewing their relevance to a psychosocial problem and the resulting intervention. The following findings emerged in response to the research questions.

\section{Overall views of psychosocial assessment}

The concept psychosocial seemed to be familiar to the participants, although they did not describe their understanding of psychosocial assessment but rather indicated what should be assessed psychosocially during antenatal care, as reflected by their various responses. As three focus group discussions were held, the responses will be categorized as follows: Focus group number 1 (Fcg 1), focus group number 2 (Fcg 2) and focus group number 3 (Fcg 3). All participants were women:

'Psycho talks about mentality ... social is maybe the environment or socialisation or anything that is affecting her socially as a human being.' (P2, Fcg1)

'My understanding of psychosocial, it means how we as midwives, really, really, going deeper into the social background of the woman, do we really ask about the social background besides the physical background, do we really ask the questions, that is something usually that does not appear on our antenatal card but do we really try to go deeper into the background, the home situation, the financial support, and the ordinary support and how the mother is feeling [emphasizing] about the current pregnancy, all the previous pregnancies, were there conditions like puerperal psychosis or whatever that could be anticipated, psychosocial support, is [sic] there people or systems that can assist in whatever way to care for this patient for example the family.' (P1, Fcg 3)

The three major themes that were developed from the participants' responses in relation to the concept 'psychosocial risk assessment' were social factors, psychological factors and assessment (Table 1). Reflected within the social and psychological themes are subthemes in a form of factors that relate to psychosocial assessment, which also provide a holistic approach to assessment during pregnancy. Psychological subthemes included the emotional, mental status and sexual abuse.

According to the participants' responses, the social factors that influenced women's psychological behaviour were existing social problems, social stigma, environmental hazards, unplanned or unwanted pregnancy, life events and cultural and economic issues. The responses of women to these social factors, as also stated by Ul Moula (2009:20-21), could be manifested psychologically through emotions that included anger and mental instability and the fact that psychosocial factors in health are conditioned or modified 
TABLE 1: The midwives' understanding of psychosocial risk assessment during pregnancy.

\begin{tabular}{|c|c|c|}
\hline Major themes & Subthemes & Participants' responses \\
\hline \multirow[t]{6}{*}{ Social risks } & Social problems & $\begin{array}{l}\text { 'Social benefits and the risk to the mother and baby, having problems inside and outside the house, anything that is affecting her } \\
\text { socially as a human being.' }\end{array}$ \\
\hline & Stigma/Discrimination & $\begin{array}{l}\text { 'The stigma and discrimination associated with HIV/AIDS, they run away from the environment where they stay as they are going to } \\
\text { be identified if they obtain dual therapy or milk for the baby.' }\end{array}$ \\
\hline & Environmental & $\begin{array}{l}\text { 'Social is the environment or socialisation, cultural values, social background, home situation and financial support, the background } \\
\text { that the woman comes from.' }\end{array}$ \\
\hline & Sexual abuse & 'Women pregnant due to rape, incest or sexual harassment.' \\
\hline & Life events & 'A woman whose husband died in a car accident while she was pregnant, and a divorced woman.' \\
\hline & Unplanned pregnancy & 'Women not ready to have a baby as some ask about abortion.' \\
\hline \multirow[t]{2}{*}{ Psychological risks } & Emotional & $\begin{array}{l}\text { 'How does the woman feel about the pregnancy.' } \\
\text { 'Sometimes you get clients that are angry and are not happy about the pregnancy.' }\end{array}$ \\
\hline & Mental & 'Psycho talks about mentality, psychological.' \\
\hline Assessment & - & $\begin{array}{l}\text { 'Assess age, working or not, the inside of the house; we are normally happy that the woman is pregnant but we do not ask about how } \\
\text { she feels, ... the environment, the type of family, social community and cultural things that affect her psychology; We should assess } \\
\text { them in totality, viewing their mental, physical and social state; We should include Maslow's Hierarchy of Needs in their assessment.' }\end{array}$ \\
\hline
\end{tabular}

by the social structures and contexts in which they exist. Participants in all three groups agreed that it is important for midwives to assess women psychosocially during antenatal care, for example, 'so that you can intervene immediately and refer to the right resource' (P3, Fcg 2). Participants indicated that psychosocial assessment did not occur routinely, unless there was an indication to go beyond the routine physical assessment. A psychosocial problem could be identified, for example, during health information sessions or when the midwife observes an unusual behaviour from a pregnant woman during a follow-up visit.

'Every time when we see the patient we just check the patient and let them go, we talk to the patient as usual ... like we know our patients; and if you notice that she is not the person you know ... is then [sic] that you find out what the problem is.' (P2, Fcg 3)

Dragonas et al. (1998:130-133) highlight that antenatal preparation provides an opportunity to confront psychosocial problems and offer psychosocial support.

Participants in all groups agreed that psychosocial assessment and psychosocial care should be included within routine antenatal care:

'Yes, I think it should be part of antenatal care ... only if the ratio of staff and patients is corrected, because it will be easy for us to identify the risk on time and to manage or intervene.' (P4, Fcg 1).

'To add on that it is important for us to ask about the psychosocial problems it's for me to understand if the pregnancy was planned ... if it was unplanned, the woman might develop conditions like hypertension.' (P4, Fcg 3)

The implication was that psychosocial risk assessment is done to a limited extent:

'... I think we need to do more as part of the assessment ... it does have to be more specific than what we are already doing ... we are already identifying some problems ... we can ask some more ... and then refer for further help.' (P5, Fcg 2)

Psychosocial assessment was considered time consuming by the participants:

'I think it is important but if a person has to be allocated for psychosocial care, you need somebody who can sit with them for hours because there are many problems now.' (P4, Fcg 2)
A reflection on staff shortage:

'It can be done, eh, there might be a challenge of the number of staff against patients because you have to give full attention to that person when she talks.' (P3, Fcg 1)

'Staff is really very, very low ... it's true if we can be more, we can attend to the women.' (P1, Fcg 1)

\section{Common psychosocial problems that were encountered by participants}

Participants provided a narrative account of their experiences of psychosocial care for pregnant women. The stories were then analysed in terms of common problems encountered, which were women suffering from HIV and not coping with the condition, unemployment, a lack of accommodation, a lack of family support, smoking, alcohol consumption, unplanned pregnancy, teenage pregnancy and poverty.

\section{Interventions used to manage problems}

Regarding the interventions that midwives took once a psychosocial risk was detected, participants described a situation which presented a particular psychosocial problem, explained the action taken and related the outcome of the interaction, as is reflected in Table 2 . The stories were analysed by viewing their relevance to a psychosocial problem and the resulting intervention.

The actions that the midwives took once a psychosocial risk was identified were: listening to the woman attentively; giving women options such as termination of pregnancy and adoption; encouraging family involvement; and advising women on applying for social support grants.

The common resources and options available for further care once a psychosocial problem was identified were considered to be: social services, psychologists, termination of pregnancy services, adoption and referral for antiretroviral therapy (ARV) for those who were HIV positive with a low CD4 count.

\section{Barriers to the provision of psychosocial assessment and care}

Participants described the obstacles to the implementation of psychosocial assessment and care in the next segment. 


\section{Identified problem}

A woman with malnutrition.

A 33-year-old carrying an unplanned pregnancy, single and on antiretrovirals.

A baby delivered at home, baby rejected by family, mother brought and wanted to leave baby in the labour ward.

Woman opting for termination of pregnancy at an advanced gestation. Woman opting for termination of pregnancy as she was unemployed. Women refusing to test for HIV.

A woman who had a disabled younger sister under her care, both unemployed, supported by partner.

Attitude conflict between midwife and woman.
Psychosocial support offered

'I advised her on correct diet and referred her to feeding schemes.'

'Counselled and referred to a psychologist.'

'I counselled and contacted family overnight, family accepted baby and sister sent to fetch mother and baby.'

'After sonar was done, and the mother saw the foetal heart decided to keep the baby [sic].'

'Family was contacted and agreed to support and discouraged her from opting for termination.'

'Counsel them again, listen to their problems and show them that there is another side of the picture.' 'Advised to apply for social grant and referred to social services.'

'Referred for second opinion to other team member to handle.'

'Be open as a midwife and not close them outside, avoid pulled or straight faces.'
Lack of experience and inadequate training on psychosocial care:

'... we have got a lot of patients with psychosocial problems, then for me personally I find that I am helpless and get frustrated because we cannot change that or we cannot sometimes assist.' (P1, Fcg 2)

Staff shortage and work overload resulting in an average midwife: woman ratio of 70:3; the increased number of pregnant women, specifically teenagers, who need special attention; overpopulation of antenatal clinics by foreigners; lack of consultation rooms and the view that social services were inactive; women often not opening up, probably fearing discrimination by midwives or victimisation by partners:

'... you find that you have a client, you want to help in every possible way, you have the resources, but the patient does not want to accept your help, that is a problem, you want to assist [emphasising], you want to refer [emphasising], you know you want to do all the possible things, but the patient is not just willing to accept your help ... you would like to refer to a social worker, the only way is to refer, now she knows that the social workers will come to her home and she will be exposed, because she is staying with this man, so whatever she is to be helped with, the man should not be aware of ...' (P1, Fcg 3)

Foreign language and women with speech and hearing disabilities; women who communicate through sign language to midwives who are not able to understand them, which often leads to poor antenatal history-taking, as is stated in the following:

'The checklist is fine but there would be those problems of language, not just ShiVenda or Siswazi, but even sign language [stressed]. Nurses were not schooled for sign language; you get a dumb-and-deaf patient, who cannot read or write, so now you have this checklist again, how would you communicate now.' (P1, Fcg 3)

'Clarity, some speak French, they can't speak English, we expect people from Malawi to speak English, we do sign language but it's a challenge, so history taking, psychosocial assessment is a challenge [laughing and giggling].' (P2, Fcg 1)

Regarding the shortage of midwives, a study on Zambian women's perception of antenatal care by Menon et al. (2010:361) concluded that overcrowding and pressure of work experienced by midwives cause stress, which may lead to them being less sensitive to the psychosocial needs of women, which could be a factor in this study.
Furthermore, participants cited a lack of formalised guidelines for psychosocial assessment and lack of a standard tool to record the information as the antenatal card is non-specific and, as such, the focus is mostly on medical conditions, as reflected by the following response:

'There must be a tool because on the green card is just a small line, it's not written clear, just says "social", therefore we ask the question "are you working?". If she says yes it's OK and if she says no, we ask her who is supporting her. If she says my mother, you write "mother supportive"... if there was a guideline regarding what to do. The green card says social, it does not say psychosocial, as such, each midwife records what she feel is appropriate.' (P1, Fcg 3)

Participants further reflected on the column that states 'social' on the Gauteng standardised antenatal card and the fact that it does not specify what of social and does not include psychological factors. 'With a checklist, I think we would be made aware of the things that we normally don't ask' (P1, Fcg 3). 'Even if it cannot be implemented now, is for the future, let it be incorporated into antenatal care, even if it can be how small it will make a difference ... to say what type of questions to ask' (P2, Fcg 3).

The social service resources were also reported as being dysfunctional:

'I have been listening to ourselves, we have been saying refer to the social worker, you know we have a problem with the social welfare, it's so bad ... unfortunately our provincial social worker is just not effective, not at all, therefore we rely on the non-government organisation to help us ... the structure is there, but the availability of the social worker, the person, it's a person! [emphasised] $[A]$ human resource, do you understand, the structure is there, this is social service...but when you go to that office you won't even get any help, it sometimes end on us to deal with those things, with the social issues of the patient.' (P1, Fcg 2)

\section{Ethical considerations}

Ethical approval was obtained from the University of Witwatersrand Human Research Ethics Committee (protocol number M081013). Permission was sought from the Provincial Health Department and from the clinics and the unit managers where interviews were conducted. Each participant was provided with sufficient and understandable information regarding the research in order for them to make a voluntary informed decision to participate. Participants 
signed the consent form before data were collected. Confidentiality and anonymity were ensured throughout by protecting the participant's identity and privacy when reporting the findings. The use of a skilled moderator and assistant moderator, welcoming of participants and an overview of the topic, ground rules which included that one person to speak at a time, listening respectfully to one other and emphasising that all participants need not agree with each other and the use of a moderator to keep the group focused, were adhered to throughout the discussion as the principles of focus group discussions (Franz 2011:1381-1383; Kruger 2002:1-7).

\section{Trustworthiness}

Lincoln and Guba's model, as described by De Vos et al. (2009:345-347), was utilised in order to ensure trustworthiness. Trustworthiness is based on how representative the description is and how justifiable the findings are. Neutrality was enhanced by direct involvement of participants in negotiating the truth through subjective accounts of personal experiences, and meanings of reality from each participant's perspective, until saturation was reached. Credibility was justified through member checking by conducting follow-up interviews with two members from each of the three groups interviewed and peer review was managed through the study being supervised by an expert in qualitative research methodology and midwifery. Data were analysed by an independent coder who is an expert in qualitative research methods and midwifery, using previously agreed-upon coding criteria in order to validate themes, which ensured consistency and dependability on audit. Transferability was enhanced by providing a thick description of the research process and respondent validation through the comparison of commonalities of responses from the different groups (Pope \& Mays 2000:94-97).

\section{Discussion}

The concept 'psychosocial; seemed to be a familiar concept for participants.The findings indicated that midwives understood and considered psychosocial care during pregnancy as an important part of antenatal care. A comprehensive assessment, which includes the physical, social and psychological aspects, is reflected within the participants' responses in Table 1.

Although participants reported a lack of formal guidelines or a tool for psychosocial care, psychosocial interaction amongst midwives and pregnant women usually occurred through empathetic perception and intuition, often in a subtle way. The assessment and support that midwives offered at the clinics, as reflected in Table 2, could, to a reasonable extent, have assisted in minimising the impact of psychosocial problems or risks on pregnant women. This is in keeping with the findings of Joseph et al. (2009:1058), who reported that a clinic-based psychosocial intervention significantly reduced psychosocial and behavioural risk factors amongst African American women during antenatal care. Listening to the woman attentively is regarded as being the appropriate first step in offering support as it allows the woman to express the problems that she is experiencing. Through attentive listening, women can be motivated to discuss the issue and, if indicated, seek further help. The results of a randomised study by Lavender and Walkinshaw (1998:217) revealed that the most effective psychosocial care includes listening, support, counselling, understanding and explanation, all of which seemed to have been applied by midwives in this study.

Most authors (Carroll et al. 2005:257; Fawole, Okunlola \& Adekunle 2008:1052; Minnaar \& Bodkin 2009:14; Namagembe 2007:1-2; Walker, McCully \& Vest 2001:146; Willinck \& Schubert 2000:10-11) recommend psychosocial care as part of routine antenatal care. The prenatal care guidelines in Group Health Incorporated Organisation (2008), also recommended that psychosocial assessment should be performed either by being included in the overall risk assessment or as a separate tool. Women should be screened for social, psychological and emotional risks, substance abuse, sexual abuse, economic status and domestic violence. The National Action Plan 2008-2010 of the beyondblue Perinatal Mental Health Consortium (St John of God Health Care n.d.) also recommends universal routine psychosocial assessment. Its strategic objective was to identify and develop a quality framework for universal implementation of routine psychosocial assessment in the perinatal period. However, little progress has been made in this regard at this stage.

Willinck et al. (2000:10-11), in a study regarding psychosocial risk assessment, concluded that psychosocial problems are prevalent during pregnancy. Furthermore, the study has also shown that the introduction of systematic psychosocial assessment during the antenatal booking visit was acceptable practice for women and midwives as it also improved the identification of psychosocial problems.

Namagembe (2007:1-2) highlighted that the experienced psychosocial problems may have an indirect influence on the woman's coping ability and may aggravate the physiological adjustment to pregnancy. Minnaar and Bodkin (2009:12-14), in a study on exploring bereavement and grief in HIV-positive pregnant women, led to a finding that women went through emotions such as denial, anger, bargaining, depression and acceptance. This response is supported by a randomised controlled trial amongst midwives and obstetricians that examined the effectiveness of the Antenatal Psychosocial Health (ALPHA) tool, revealing that $86 \%$ of respondents would use the tool as a standard practice to assess pregnant women psychosocially (Matthey 2005:268).

The conclusion and recommendation of the randomised controlled trial was that over and above the standard HIV programme, midwives should allow and encourage women to share their feelings, provide counselling, support women and offer care based on individual needs. As stated by the Royal College of Midwives (2000:224), legislation enables midwives to provide holistic care during pregnancy without 
recourse to other health professionals, which is also the situation within the South African context, as the South African Nursing Council Midwifery Regulations (South African Nursing Council 1984) allows midwives to assess women psychosocially. This is evidenced by the inclusion of the psychosocial aspect within Regulation 2598 of 1984 (Scope of Practice for Registered Midwives) as amended, as indicated by concepts such as optimum mental health, counselling of individuals, monitoring trauma, stress and anxiety, an environment that promotes the mental health of the mother, advocacy, coordination of care and referral of the women.

\section{Limitations of the study}

Some information might have been withheld by participants who were reluctant to share their perception of psychosocial care in the presence of colleagues. The fact that the researcher is also a midwife could have contributed to participants being uncomfortable in sharing information.

\section{Conclusion}

From the findings, it was evident that psychosocial problems exist during pregnancy, with HIV contributing significantly. Midwives displayed an awareness of psychosocial risks as they encounter them on daily basis. Midwives regard psychosocial assessment as an important aspect in caring for pregnant women and are willing to assess women psychosocially. However, they feel that they are not adequately equipped to do so for various reasons, for example a lack of guidelines or a tool to assess women psychosocially. The resources for referral for psychosocial care were also reported to be inadequate. The general finding of this study provides a basis for incorporation of psychosocial care into routine antenatal care.

\section{Recommendations Midwifery practice}

The Gauteng antenatal card used for routine antenatal care focuses on the physiological aspects of pregnancy and provides only a small column titled 'social'. In addition to physical care, the antenatal booking history should also focus on psychosocial risks in order to identify women who need specialised supportive care. Psychosocial assessment can be done informally by asking the woman how she is feeling and whether she has any concerns, either currently or expected when the baby is born. Any response that indicates possible stress should be taken seriously, and appropriate support or intervention should be offered to the woman. The progress report column of the Gauteng Province antenatal card can be used for recording psychosocial factors, as the space assigned for social problems is inadequate.

\section{Midwifery education}

Psychosocial assessment and psychosocial care during pregnancy should be emphasised in the curriculum for midwives. In-service training on psychosocial care should be regularly offered to midwives.

\section{Research}

In response to the findings of the focus group discussions, clinical guidelines for use in psychosocial risk assessment and psychosocial care need to be formulated.

\section{Acknowledgements}

The authors thank the midwives who willingly participated in the focus group discussions, the University of Witwatersrand for financial support and Jennefer Hesk for language editing.

\section{Competing interests}

The authors declare that they have no financial or personal relationship(s) which may have inappropriately influenced them in writing this article.

\section{Authors' contributions}

J.M.M. (University of South Africa) collected data, conducted data analysis and compiled the manuscript. A.R.R. and G.L. (University of the Witwatersrand) assisted with data analysis and made conceptual contributions.

\section{References}

Anderson, K.N. \& Anderson, L.E., 1990, Mosby's pocket dictionary of medicine, nursing, \& allied health, 2nd edn., The CV Mosby Company, St Louis, MS.

Anderson, D., Harris, M. \& Madl, R., 1998, 'Women and violence', in A. Smith and C. Rogers-Clark (eds.), Women's health: A primary health care approach, pp. 120-139, MacLennan and Petty, Sydney.

Austin, M.P. \& Lumley, J., 2003, 'Antenatal screening for postnatal depression: A systematic review', Acta Psychiatrica Scandinavica 107(1), 10-17. http://dx.doi. org/10.1034/j.1600-0447.2003.02024.x

Bryce, R.L., Stanley, F.J. \& Enkin, M.W., 1988, 'The role of social support in the prevention of preterm birth', Birth 15(1), 19-23. http://dx.doi.org/10.1111/j.1523536X.1988.tb01078.x

Carroll, J.C., Reid, A.J., Biringer, A., Midmer, D., Glazier, R.H., Wilson, L. et al., 2005, 'Effectiveness of the Antenatal Psychosocial Health Assessment (ALPHA) form in detecting psychosocial concerns: a randomized controlled trial', Canadian Medical Association Journal 173(3), 253-259. http://dx.doi.org/10.1503/cmaj.1040610

Coussons-Read, M.E., Okun, M.L., Schmitt, M.P. \& Giese, S., 2005, 'Prenatal stress alters cytokine levels in a manner that may endanger human pregnancy', Psychosomatic Medicine 67(4), 625-631. http://dx.doi.org/10.1097/01.psy.0000170331.74960.ad

De Vos, A.S., Strydom, H., Fouche, C.B. \& Delport, C.S.L., 2009, Research at grassroots for the social sciences and human services professions, 3rd edn., Van Schaik, Pretoria.

Dragonas, T. \& Christodoulou, G.N., 1998, 'Prenatal care', Clinical Psychology Review 18(2), 127-142. http://dx.doi.org/10.1016/S0272-7358(97)00085-8

Fawole, A.O., Okunlola, M.A. \& Adekunle, A.O., 2008, 'Clients' perceptions of the quality of antenatal care', Journal of the National Medical Association 100(9), 1052-1058.

Feldman, P., 2000, Social support during pregnancy can affect fetal growth and birth weight, Center for the Advancement of Health, viewed 07 July 2007, from http:// www.cfah.org/hbns/newsrelease/social9-22-00.cfm (link no longer valid).

Franz, N.K., 2011, 'The unfocused focus group: benefit or bane?', The Qualitative Report 16(5), 1380-1388, viewed 07 February 2014, from http://www.nova.edu/ ssss/QR/QR16-5/franz.pdf

Frisch, N.C., 2001, 'Standards for holistic nursing practice: a way to think about our care that includes complementary and alternative modalities', The Online Journal of Issues in Nursing 6 (2), 4

Gauteng Department of Health, 1997, Antenatal care policy document, Directorate: Mother and Child Health, Gauteng Provincial Government, Marshalltown.

Glazier, R.H., Elgar, F.J., Goel, V. \& Holzapfel, S., 2004, 'Stress, social support, and emotional distress in a community sample of pregnant women', Journal of Psychosomatic
Obstetrics and Gynaecology 25(3-4), 247-255. http://dx.doi.org/10.1080/ 01674820400024406

Group Health Incorporated, 2008, Pre-natal care guidelines, viewed 07 August 2008 , from http://www.ghi.com/default.aspx?Page=240 (link no longer valid).

Hildingsson, I. \& Häggström, T., 1999, 'Midwives' lived experiences of being supportive to prospective mothers/parents during pregnancy', Midwifery 15(2), 82-91. http:// dx.doi.org/10.1016/S0266-6138(99)90003-7

Joseph, J.G., El-Mohandes, A.A.E., Kiely, M., El-Khorazaty, M.N., Gantz, M.G., Johnson, A.A. et al., 2009, 'Reducing psychosocial and behavioral pregnancy risk factors: results of a randomized clinical trial among high-risk pregnant African American women', American Journal of Public Health 99(6), 1053-1061. http://dx.doi.org/ 10.2105/AJPH.2007.131425 
Krueger, R.A., 2002, Designing and conducting focus group interviews, University of Minnesota, viewed 07 February 2014, from http://media.usm.maine.edu/ lenny/ FOCUS\%20GROUP\%20RESEARCH/Krueger-FocusGrouplnterviews.pdf

Lavender, T. \& Walkinshaw, S.A., 1998, 'Can midwives reduce postpartum psychological morbidity? A randomized trial', Birth 25(4), 215-219. http://dx.doi.org/10.1046/ j.1523-536X.1998.00215.x

Mamelle, N.J., 2001, 'Psychological prevention of early pre-term birth: a reliable benefit', Biology of the Neonate 79(3-4), 268-273.

Matthey, S., 2005, 'Assessing for psychosocial morbidity in pregnant women', Canadian Medical Association Journal 173(3), 267-269. http://dx.doi.org/10.1503/cmaj.050727

Menon, J.A., Musonda, V.C.T. \& Glazebrook, C., 2010, 'Perception of care in Zambian women attending community antenatal clinics', Educational Research 1(9), 356-362.

Merriam, S.B., 2002, 'Qualitative research in practice: examples for discussion and analysis', Jossey-Bass, San Francisco.

Minnaar, A. \& Bodkin, C., 2009, 'The mourning process of HIV-positive pregnant women', Africa Journal of Nursing and Midwifery 11(2), 5-17.

Namagembe, I., 2007, 'Prevalence of stress, depression, alcohol use, and social support among HIV infected and uninfected pregnant women in Uganda', paper presented at the APHA 135th Annual Meeting and Expo, Washington, DC, 3-7 November.

National Institute for Clinical Excellence, 2003, Antenatal care: Routine care for the healthy pregnant woman, National Collaborating Centre for Women's and Children's Health (UK), RCOG Press, London.

Onwuegbuzie, A.J., Dickinson, W.B., Leech, N.L. \& Zoran, A.G., 2009, 'A qualitative framework for collecting and analyzing data in focus group research', International Journal of Qualitative Methods 8(3), 1-21.

Pope, C. \& Mays, N., 2000, Qualitative research in health care, 2nd edn., British Medical Journal Books, London.
Royal College of Midwives, 2000, 'Assessing and managing risk in midwifery practice', RCM Midwives Journal 3(7):224-225.

South African Nursing Council, 1984, Government Notice No. R2598 of 1984, as amended: Regulations relating to the scope of practice of persons who are registered or enrolled under the Nursing Act, 1978, SANC, Pretoria.

Stahl, K. \& Hundley, V., 2003, 'Risk and risk assessment in pregnancy - do we scare because we care?', Midwifery 19(4), 298-309. http://dx.doi.org/10.1016/S02666138(03)00041-X

St John of God Health Care, n.d., The beyondblue perinatal mental health consortium: National Action Plan 2008-2010, viewed 07 February 2014, from https://www.
beyondblue.org.au/docs/default-source/8.-perinatal-documents/bw0128overview-of-the-strategic-and-op-aspects-of-nap.pdf?sfvrsn=2

Suppaseemanont, W., 2006, 'Depression in pregnancy: drug safety and nursing management', The American Journal of Maternal Child Nursing 31 (1), 10-15. http://dx.doi.org/10.1097/00005721-200601000-00004

UI Moula, S.M., 2009, Health care behavior. Factors influencing health care behavior of a person, doctoral thesis, blog archive, viewed 12 May 2011, from http:// healthcarebehaviorshamim.blogspot.com/2009/06/psychosocial-factorsrelated-t (article no longer hosted at this URL).

Walker, S.D., McCully, L. \& Vest, V., 2001, 'Evidence-based prenatal care visits: when less is more', Journal of Midwifery \& Women's Health 46(3), 146-151. http:// dx.doi.org/10.1016/S1526-9523(01)00120-9

Walter, S., 1999, 'Holistic health', in N. Allison (ed.), The illustrated encyclopedia of body-mind disciplines, pp. 1-4, American Holistic Health Association, The Rosen Publishing Group, New York.

Willinck, L. \& Schubert, R., 2000, 'Antenatal psychosocial risk assessment project', Australian College of Midwives Incorporated Journal 13(3), 7-12. http://dx.doi. org/10.1016/S1031-170X(00)80005-7

World Health Organization, 1998, Word Health Day. Safe motherhood: Every pregnancy faces a risk, WHO, Geneva. 